\title{
Epidemiology of United States Pediatrics Sports-Related Ocular Injuries from 2000-2019
}

\section{Parth S Patel ${ }^{1,2}$, Aditya Uppuluri ${ }^{1}$, Marco A Zarbin ${ }^{1}$ and Neelakshi Bhagat $^{1 *}$}

${ }^{1}$ Institute of Ophthalmology and Visual Sciences; Rutgers New Jersey Medical School Newark, NJ, USA

${ }^{2}$ Rutgers Robert Wood Johnson Medical School Piscataway, NJ, USA

*Corresponding Author: Neelakshi Bhagat, Professor of Ophthalmology, Institute of Ophthalmology and Visual Sciences; Rutgers New Jersey Medical School Newark, NJ, USA.
Received: February 15, 2021;

Published: March 06, 2021

(C) All rights are reserved by Neelakshi

Bhagat., et al.

\begin{abstract}
Objective: To characterize the epidemiology of sports-related ocular injuries in school aged children ages 5 - 18 in the United States, $2000-2019$.

Methods: Data was sourced from the National Electronic Injury Surveillance System for this retrospective epidemiology study. Inclusion criteria for this study included: patient age between 5 - 18 years, eye injury between 2000 and 2019, and eye injury involving sports at all geographic sites. Data were divided into two age groups: 5 - 11 and 12 - 18 years.

Results: There were an estimated 264,648 ED visits for sports-related ocular injury of which $73 \%$ were males and $42 \%$ between the ages 5 - 11 years. Over $96 \%$ of children were treated and released from the ED, suggesting minor injury. The sports most commonly associated with eye injuries were basketball, baseball/softball, swimming, football, and soccer. In terms of location, $56 \%$ of injuries occurred on the court. In the 5 - 11 cohort, home was the most common location for off-court injuries, while in children aged 12 - 18 , most off-court injuries occurred at school.

Conclusion: Sports-related pediatric ocular injuries between 2000 - 2019, mostly were contusions in older male children and were encountered primarily on the basketball court. Off-court injuries occurred mainly at school.
\end{abstract}

Keywords: Pediatrics; Eye; Sports; Basketball; Baseball/Softball

\section{Introduction}

The annual average emergency department (ED) visits for eye injuries reported in the literature are approximately 2.4 million [1]. Sports-related ocular injuries are one of the leading causes for ED visits in the pediatric population [2-6]. Understanding the demographics of sports-related ocular injury can allow for multifaceted interventions with recommendations for safer use of equip- ment, safety regulations within organized youth sports and general education of the population.

\section{Aim of the Study}

The goal of this study is to characterize the epidemiology of sports-related ocular injury in school children between the ages of 5 - 18 years. 


\section{Materials and Methods}

This study utilizes data sourced from the National Electronic Injury Surveillance System (NEISS); an injury surveillance system run by the Consumer Product Safety Commission primarily to gather data on consumer-product related injuries. The NEISS database encompasses a representative sample of 100 US hospital emergency departments. The inclusion criteria for this study are patient age between 5 and 18 years and injury involving the eye between January 1, 2000 and December 31, 2019 caused by a sport-related consumer product (on or off the court). Data were divided into two age groups: 5 - 11 and 12 - 18 years of age. Prior to analysis, data weights were applied to make estimates representative of the national population.

\section{Results}

Between 2000 - 2019, there were 264,648 total ED visits for sports-related ocular injuries for children aged 5 - 18, of which 192,601 (72.8\%) were males (Table 1). The majority of injuries $(153,974 ; 58.2 \%)$ were seen in the older cohort, 12 - 18 and on the court $(103,465 ; 55.6 \%)$ (Table 2$)$. The most common locations for known off the court injuries was school $(42,154 ; 23 \%)$ and home $(29,353 ; 16 \%)$, with more injuries at home in the younger age cohort and at school in the older cohort.

\begin{tabular}{|l|c|c|}
\hline \multicolumn{1}{|c|}{ Sports } & Males (n) & Females (n) \\
\hline Basketball & $47,495(24.7 \%)$ & $10,477(14.5 \%)$ \\
\hline Baseball/Softball & $29,032(15.1 \%)$ & $11,008(15.3 \%)$ \\
\hline Football & $23,814(12.4 \%)$ & - \\
\hline Swimming & $19,830(10.3 \%)$ & $16,415(22.8 \%)$ \\
\hline Soccer & $11,836(6.1 \%)$ & $6,532(9.1 \%)$ \\
\hline $\begin{array}{l}\text { Miscellaneous } \\
\text { Ball Games }\end{array}$ & $10,943(5.6 \%)$ & $3,185(4.4 \%)$ \\
\hline Racquet Sports & $7,377(3.8 \%)$ & $2,957(4.1 \%)$ \\
\hline
\end{tabular}

Table 1: Estimated number of sports-related ocular injuries by gender between 2000 and 2019. '-': Signifies a relatively small proportion of injury.

Ocular contusions were the most common diagnoses for both age groups (younger: $48.6 \%$ and older: $52.5 \%$ ). The most common sports associated with ocular injuries included basketball (21.9\%), baseball/softball (15.1\%), swimming (13.7\%), football (9.5\%),

\begin{tabular}{|l|c|c|}
\hline \multicolumn{1}{|c|}{ Sports } & On court injuries (n) & $\begin{array}{c}\text { Off court } \\
\text { injuries (n) }\end{array}$ \\
\hline Basketball & $17,257(20.9 \%)$ & $23,780(23 \%)$ \\
\hline Football & $8,527(10.3 \%)$ & $10,099(9.8 \%)$ \\
\hline Swimming & $7,585(9.2 \%)$ & $13,551(13.1 \%)$ \\
\hline Baseball/softball & $7,180(8.7 \%)$ & $22,619(21.9 \%)$ \\
\hline $\begin{array}{l}\text { Miscellaneous } \\
\text { Ball Games }\end{array}$ & $5,435(6.6 \%)$ & $2,229(2.2 \%)$ \\
\hline Bicycling & $5,434(6.6 \%)$ & - \\
\hline Soccer & $3,761(4.6 \%)$ & $9,408(9.1 \%)$ \\
\hline
\end{tabular}

Table 2: Estimated number of sports-related injuries on and off the court between 2000 and 2019. '-': Signifies a relatively small proportion of injury.

soccer (6.9\%), and bicycling (4.3\%), which cumulatively accounted for nearly $70 \%$ of all injuries.

Table 1 and figure 1 show the distribution and frequency of the sports associated with eye injury by gender and age.

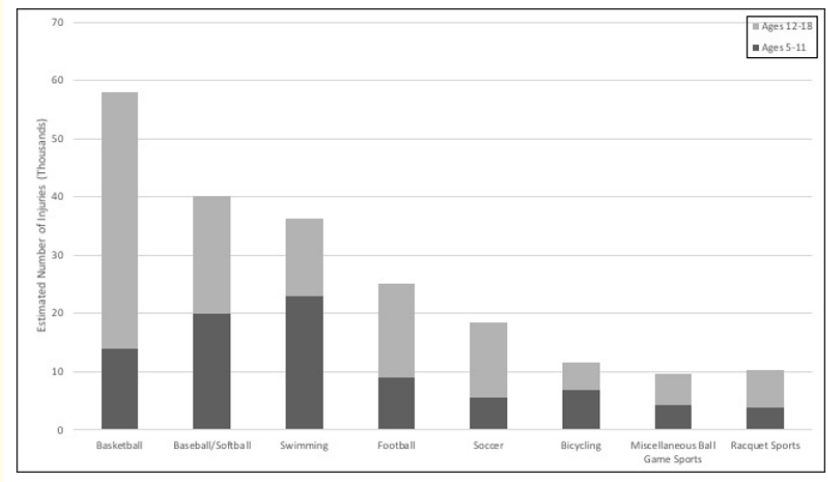

Figure 1: Estimated number of ocular injuries for selected sports by age cohorts.

There were an estimated 39,719 swimming-associated injuries. The most common diagnoses were dermal/conjunctival injury accounting for $49.3 \%$ of ocular injuries followed by ocular contusions $(21.6 \%)$ and chemical burns (5.6\%). The male-to-female ratio of injury was 1.2:1. 
Most patients (96.5\%) were treated and released from the ED, suggesting a minor injury. An estimated 3,817 (1.4\%) patients were treated and transferred while 2,167 $(0.8 \%)$ patients were hospitalized. The male-to-female ratio of those hospitalized due to sport-related ocular injury was 2.9:1. There were an estimated 3,963 open globe injuries (OGI) with $1.6 \mathrm{x}$ more OGIs seen in the older cohort compared to the younger, 5 - 11 . One-fourth of children hospitalized for an ocular injury had an OGI.

\section{Discussion}

The findings illustrate that from 2000 - 2019, most sports-related pediatric ocular injuries were seen in older male children, in the 12 - 18 age cohort, on the basketball court. The male-to-female ratios in the younger and older age groups were 2.4:1 and 2.9:1, respectively. The most common sport-associated with injury in the younger 5 - 11 cohort was swimming compared to basketball in the 12 - 18 age group.

Basketball injuries accounted for over one-fifth of injuries in the pediatric population in this study similar to what is reported in the literature [5]. Eye injuries in basketball most often are due to being hit inadvertently by another player while baseball-associated ocular injuries are more often due to the bat or ball $[7,8]$. These injuries range from benign injuries, such as conjunctival hemorrhage, to severe injuries, such as retinal detachment [9]. Specific recommendations have been released by regulatory bodies such as the American Academy of Pediatrics and American Academy of Ophthalmology regarding the importance of eye safety in youth sports, including recommendations regarding the types of polycarbonate lenses children should wear $[10,11]$.

A statement from the National Federation of State High School Associations mandated the use of protective eyewear in high school athletes for field hockey during the 2011 season. The mandate led to a reduced incidence of eye/orbital injuries and fewer severe eye/orbital and head/face injuries [12]. This mandate was made voluntary in 2020 since the ASTM goggles did not protect against direct ball to eye injuries, and the goggles were not available for all athletes, namely those with corrective lenses. This ruling is being changed to allow for the switch from goggles to a face mask [13].

Swimming and football collectively accounted for nearly $25 \%$ of eye injury related ED visits. Football-related ocular injuries occur during active game play. Certain football helmet face shields/vi- sors are impact resistant and may decrease ocular injury, but they do lose resistance with everyday use; hence, regular replacements or inspection is indicated $[14,15]$. In one study, addition of an eye shield to head gear had an insignificant effect on reaction time and target detection when compared to helmet-only use in NCAA division 1 athletes [16]. As for swimming-associated ocular injuries, the most common injuries were dermal/conjunctival injury. Common preventative measures include wearing tight-fitting goggles to prevent ocular irritation from chlorinated pools. It is important to avoid the use of contact lenses when swimming since even 30 minutes of use of contacts in pools is enough time for bacterial colonization with increased risk for a variety of sight-threatening microbial corneal infections $[17,18]$. Use of lubricating eye drops and washing one's face with freshwater after swimming can help to avoid eye damage, especially within the 5 - 11 age group [19].

Of the off-court injuries noted in this study, the home and school settings represented the top two locations for younger and older groups, respectively. Though most pediatric patients with ocular injuries presenting to the ED were treated and discharged, approximately 2,000 were hospitalized due to injuries. The findings in this report can be used by youth sport safety regulatory bodies with an emphasis on organized basketball, baseball/softball, swimming, and football to revise and adhere to safety guidelines [10,11].

\section{Limitations}

The total number of injuries identified is likely an underrepresentation of the true frequency of pediatric ocular injury as NEISS provides information for ocular injuries presenting to the ED. Thus, NEISS does not capture injuries managed at home, in urgent care settings, or with community ophthalmologists and primary care physicians. In addition, the data could be biased toward an uninsured or under-insured population who are more likely to utilize the ED instead of a community physician. Furthermore, NEISS captures data associated with consumer-product injuries based on narratives written in the electronic health record. Vague descriptions may lead to exclusion from the database.

\section{Conclusion}

Most pediatric sports-related ocular injuries occur in older children (12 - 18 years of age) in association with basketball, baseball/ softball, swimming, and football. Advising youth sports regulatory bodies, parents, primary care physicians, and athletes on current trends and proper precautions may mitigate injuries in the future. 


\section{Conflict of Interest}

None to declare.

\section{Funding and Grants}

There were no funding or grants for this manuscript.

\section{Bibliography}

1. CDC. National Hospital Ambulatory Medical Care Survey.

2. Simon TD., et al. "Emergency Department Visits Among Pediatric Patients for Sports-related Injury". Pediatric Emergency Care 22.5 (2006): 309-315.

3. Chen AJ., et al. "Age and consumer product-related eye injuries in the United States". Rhode Island Medical Journal 97.1 (2014): 44-48.

4. Cross JM., et al. "Pediatric eye injuries related to consumer products in the United States, 1997-2006". Journal of American Association for Pediatric Ophthalmology and Strabismus 12.6 (2008): 626-628.

5. Pollard KA., et al. "Pediatric Eye Injuries Treated in US Emergency Departments, 1990-2009". Clinical Pediatrics 51.4 (2011): 374-381.

6. Armstrong GW., et al. "Pediatric eye injuries presenting to United States emergency departments: 2001-2007". Graefe's Archive for Clinical and Experimental Ophthalmology 251.3 (2012): 629-636.

7. Karlson TA and Klein BE. "The Incidence of Acute HospitalTreated Eye Injuries". Archives of Ophthalmology 104.10 (1986): 1473-1476.

8. Heimmel MR and Murphy MA. "Ocular Injuries in Basketball and Baseball”. Current Sports Medicine Reports 7.5 (2008): 284288.

9. Susanne Medeiros. "Madness: Basketball Is the Leading Cause of Eye Injuries”. American Academy of Ophthalmology (2019).

10. Protective Eyewear for Young Athletes. "American Academy of Pediatrics Committee on Sports Medicine and Fitness and American Academy of Ophthalmology, Eye Health and Public Information Task Force". Pediatrics (2004).

11. Protective Eyewear for Young Athletes. AAP and AAO Communications Advisory Board (2013).

12. Kriz PK., et al. "Eye Protection and Risk of Eye Injuries in High School Field Hockey". Pediatrics 136.3 (2015).
13. High School Field Hockey Eyewear Rule Altered for 2020 Season. (2020)". National Federation of State High School (2020).

14. Schmidt JD., et al. "Does Visual Performance Influence Head Impact Severity Among High School Football Athletes?" Clinical Journal of Sport Medicine (2014): 1.

15. Zimmerman AB., et al. "Intercollegiate usage schedule and the impact resistance of used football helmet faceshields". $O p$ tometry - Journal of the American Optometric Association 82.5 (2011): 274-283.

16. Miller RA., et al. "Effects of Protective American Football Headgear on Peripheral Vision Reaction Time and Visual Target Detection in Division I NCAA Football Players". Sports 7.9 (2019): 213.

17. Choo J., et al. "Bacterial Populations on Silicone Hydrogel and Hydrogel Contact Lenses after Swimming in a Chlorinated Pool". Optometry and Vision Science 82.2 (2005): 134-137.

18. Arshad M., et al. "Water Exposure and the Risk of Contact LensRelated Disease". Cornea 38.6 (2019): 791-797.

19. What You Should Know About Swimming and Your Eyes. American Academy of Ophthalmology (2016).

\section{Assets from publication with us}

- Prompt Acknowledgement after receiving the article

- Thorough Double blinded peer review

- Rapid Publication

- Issue of Publication Certificate

- High visibility of your Published work

Website: www.actascientific.com/

Submit Article: www.actascientific.com/submission.php

Email us: editor@actascientific.com

Contact us: +919182824667 